\title{
Microstructure and ferroelectric properties of spark plasma sintered Li substituted $\mathrm{K}_{0.5} \mathrm{Na}_{0.5} \mathrm{NbO}_{3}$ ceramics
}

\author{
Canhan SEN, Berk ALKAN, Ipek AKIN, Onuralp YUCEL, Filiz Cinar SAHIN and Gultekin GOLLER \\ Istanbul Technical University, Metallurgical and Materials Engineering Department, 34469 Maslak, Istanbul, Turkey
}

\begin{abstract}
Potassium sodium niobate (KNN) is a well known piezoelectric material and a developing candidate for replacing lead based high performance piezoceramics due to limitations of hazardous materials in electronic devices. Lithium substitution in KNN structure leads a crystal transition from orthorhombic to tetragonal symmetry at room temperature and enhances ferroelectric properties. In this study, lithium substituted KNN piezoceramics with high relative densities were prepared by spark plasma sintering (SPS). Densification, crystal structure, microstructure and ferroelectric behavior of the samples were investigated. It was observed that lithium niobate based secondary phases exist in sintered KNN ceramics. These secondary phases showed significant effects on ferroelectric properties. Maximum $\left(P_{\mathrm{m}}\right)$ and remnant $\left(P_{\mathrm{r}}\right)$ polarizations were determined as 27 and $20 \mu \mathrm{C} / \mathrm{cm}^{2}$, respectively for pure $\mathrm{KNN}$ at the electric field of $20 \mathrm{kV} / \mathrm{cm}$. When the electric field was increased to $30 \mathrm{kV} / \mathrm{cm}, P_{\mathrm{m}} \mathrm{did}$ not change significantly, but remained below $P_{\mathrm{r}}$. For Li substituted samples, $\boldsymbol{P}_{\mathrm{r}}$ decreased with increasing $\mathrm{Li}$ content.
\end{abstract}

(C2011 The Ceramic Society of Japan. All rights reserved.

Key-words : Lead free piezoceramics, Niobates, Perovskites, Sintering, Ferroelectric properties

[Received January 21, 2011 ; Accepted March 23, 2011]

\section{Introduction}

PZT $\left(\mathrm{PbZrTiO}_{3}\right)$ is a piezoelectric crystal which has a wide spread usage as ultrasonic transducers, sensors and actuators. However, harmful effects of $\mathrm{Pb}$ content on environment promotes a pursuit of new high performance lead-free perovskite crystals. ${ }^{1)}$ Potassium Sodium Niobate $(\mathrm{KNN})$ is a well known lead-free piezoelectric ceramic material which is a solid solution of $\mathrm{NaNbO}_{3}$ and $\mathrm{KNbO}_{3}$.

Until a few years ago, there have been only a few reports about the piezoelectricity of $\mathrm{NaNbO}_{3}, \mathrm{KNbO}_{3}$ and $\mathrm{NaNbO}_{3}-\mathrm{KNbO}_{3}$ ceramics which exhibit an important combination of electrical and mechanical properties and environmentally friendly character, probably because of their poor sinterability and the high volatility of the sodium and potassium components during sintering at high temperatures and long sintering times. For alkaline niobate ceramics, accurate process control is required in order to obtain compositional homogeneity. These challenges could be accomplished by using the SPS technique. In this technique, a compact powder can be sintered to high density under a uniform heating at relatively lower temperatures and in much shorter sintering periods compared with other sintering methods including pressureless sintering, hot pressing, and/or hot isostatic pressing. ${ }^{2-4)}$

In the SPS process, a pulsed direct current passes through a graphite punch rods and dies simultaneously with a uniaxial pressure. The microstructure and volatilization of sodium and potassium can be controlled by a fast heating rate and shorter processing times. ${ }^{5)}$

It was reported that, pure KNN sintered with SPS have a compatible bulk density with hot press, as $4.48 \mathrm{Mg} / \mathrm{m}^{3}$. ${ }^{2), 6), 7)}$ Also, it is possible to modify crystal structure of $\mathrm{KNN}$ with several dopants in order to obtain higher ferroelectric and piezoelectric properties. $\mathrm{LiNbO}_{3}, \mathrm{SrTiO}_{3}, \mathrm{LiTaO}_{3}$ and $\mathrm{LiSbO}_{3}$

\footnotetext{
Corresponding author: G. Goller; E-mail: goller@itu.edu.tr
}

are mostly substituted compounds. ${ }^{8)-11)}$ The highest piezoelectric properties of KNN can be obtained close to morphotropic phase boundary (MPB) at a composition where $\mathrm{K} / \mathrm{Na}$ ratio approximately equals to $1{ }^{7)}$ MPB states the existence of two different crystal structures together. ${ }^{12), 13)} \mathrm{KNN}$ is in orthorhombic crystal structure at room temperature and it has orthorhombic-tetragonal crystal transition at $224^{\circ} \mathrm{C} .{ }^{14)}$ Compared to orthorhombic phase, tetragonal $\mathrm{KNN}$ represents favorable piezoelectric features due to its higher crystal symmetry. Lithium substitution distorts the orthorhombic unit cell and originates the constitution of a far amount of tetragonal crystal phase in KNN representing MPB at room temperature. ${ }^{12)-15)}$ There are few papers in literature about lithium substituted potassium sodium niobate (KLNN) type ceramics which were produced using SPS technique. ${ }^{15), 16)}$

In this study, the effects of Li substitution on the microstructural and ferroelectric properties of spark plasma sintered $\left(\mathrm{K}_{0.5} \mathrm{~N}_{0.5}\right)_{1-x} \mathrm{Li}_{x} \mathrm{NbO}_{3}$ ceramics (KLNN) were investigated.

\section{Experimental}

Commercial lithium carbonate $\left(\mathrm{Li}_{2} \mathrm{CO}_{3}\right.$, Merck, 99.0\%), sodium carbonate (Merck, $99.9 \%, \mathrm{Na}_{2} \mathrm{CO}_{3}$ ), potassium carbonate $\left(\mathrm{K}_{2} \mathrm{CO}_{3}\right.$, Merck, $\left.99.0 \%\right)$ and niobium oxide $\left(\mathrm{Nb}_{2} \mathrm{O}_{5}\right.$, Alfa-Aesar, 99.9\%, 325 mesh) were used as starting powders for synthesis of Li modified KNN powders via favorable route called as mixed oxides solid state reactions. ${ }^{17)}$ These hygroscopic materials were kept in an oven at $96^{\circ} \mathrm{C}$ to avoid absorption of water. Oxide and carbonates were balanced in stoichiometric ratio, then ball milled in a polyethylene bottle (Nalgene, $250 \mathrm{ml}$ ) for $24 \mathrm{~h}$ at $210 \mathrm{rpm}$ using ethanol media with a mixture of YSZ balls in different diameters. Homogeneously milled and mixed composition were calcined at $850^{\circ} \mathrm{C}$ for $2 \mathrm{~h}$ with a heating rate of $5^{\circ} \mathrm{C} / \mathrm{min}$. Different compositions of $\left(\mathrm{K}_{0.5} \mathrm{~N}_{0.5}\right)_{1-x} \mathrm{Li}_{x} \mathrm{NbO}_{3}$ (where $x=0,2$, $4,6,8$ and 10) were prepared by using this route.

A graphite die $50 \mathrm{~mm}$ in inner diameter was filled with the calcined powder mixtures, followed by sintering using SPS apparatus (SPS-7.40 MK-VII, SPS Syntex Inc.) at $980-1085^{\circ} \mathrm{C}$ 
for $180 \mathrm{~s}$ with a heating rate of $1.7^{\circ} \mathrm{C} / \mathrm{s}$ in a vacuum. A graphitic sheet was placed between the punches and the powder, and between the die and the powder for easy removal and better conductivity. A uniaxial pressure of $40 \mathrm{MPa}$ and a pulsed direct current ( $12 \mathrm{~ms} / \mathrm{on}, 2 \mathrm{~ms} / \mathrm{off})$ were applied during the entire SPS process. The uniaxial pressure was released during cooling for all samples. An optical pyrometer, focused on a small hole at the surface of the graphite die, was used to measure and adjust the temperature. The current was controlled manually, and linear shrinkage of the specimens during SPS process was continuously monitored by displacement of the punch rods. Maximum density was generally achieved when the shrinkage of specimen was stopped at a certain temperature. Thus, in this study, final sintering temperature for each composition was determined at the temperature when the shrinkage stopped. The effect of thermal expansion of the graphite punch rods with increasing temperature on displacement of the specimens was negligible. The initial thickness of powder compacts was approximately $7 \mathrm{~mm}$ and reduced to $4 \mathrm{~mm}$ at the end of the sintering process. The sintered specimens were in the form of pellets $50 \mathrm{~mm}$ in diameter and $4 \mathrm{~mm}$ thick and characterized after sand-blasted in order to remove the graphitic sheet.

After sintering process, heat treatments were applied to all samples at $900^{\circ} \mathrm{C}$ for $30 \mathrm{~min}$ in an open atmosphere in order to remove the residual stresses which were originating from fast sintering process of SPS. Annealing period was kept as short as possible to avoid grain growth. The bulk densities of the specimens were measured by the Archimedes' method and converted to relative density by using theoretical densities. The fractured surfaces of the specimens were investigated by field emission scanning electron microscope (JEOL JSM 7000F, Japan) with an acceleration voltage of $10 \mathrm{kV}$. The crystalline phases and crystallographic analyses of the annealed ceramics were performed by X-ray diffractometry (Rigaku Miniflex, Japan) in the $2 \theta$ range of $10-80^{\circ}$ with $\mathrm{Cu} \mathrm{K} \alpha$ radiation. For the investigation of ferroelectric properties, samples were prepared with a thickness of $1.5 \mathrm{~mm}$ using mechanical polishing and polished surfaces were coated with silver paste. The silver paste was fired at $650^{\circ} \mathrm{C}$ for $30 \mathrm{~min}$.

Ferroelectric properties of synthesized ceramics with different compositions were investigated with ferroelectric material test system (Radiant Precision LC ferroelectric test system, U.S.). Different polarization electric field intensities and cycle periods were used to perform the tests of ferroelectric behavior of different KLNN compositions.

\section{Results and discussion}

\subsection{Phase analysis and crystallography}

Figure 1 shows the XRD patterns of KNN and KLNN specimens sintered at $975-1090^{\circ} \mathrm{C}$ for $180 \mathrm{~s}$. $\mathrm{KNN}$ phases were identified using orthorhombic $\mathrm{KNbO}_{3}$ (JCDPS: 32-0822) phase due to the lack of $\mathrm{K}_{0.5} \mathrm{Na}_{0.5} \mathrm{NbO}_{3}$ solid solution card. This phase is a member of family of perovskite structures which is formulated as $\mathrm{ABO}_{3}$ where $\mathrm{A}$ and $\mathrm{B}$ denote the atoms invade the corners and body centered positions of a unit cell respectively. ${ }^{13)}$

Pure KNN was well suited to diffraction pattern of foresaid $\mathrm{KNbO}_{3}$ phase representing fully orthorhombic structure. A slight shifting in peak positions was also observed and evaluated as originating from replacement of $\mathrm{K}$ with $\mathrm{Na}$ ions in the unit cell.

For the Li substituted samples, relative intensities of the peaks originating from the atomic planes (100), (200), (210), (211) of tetragonal phase increased steadily with increasing Li content. Furthermore, peaks of (101) and (110) planes became visible at

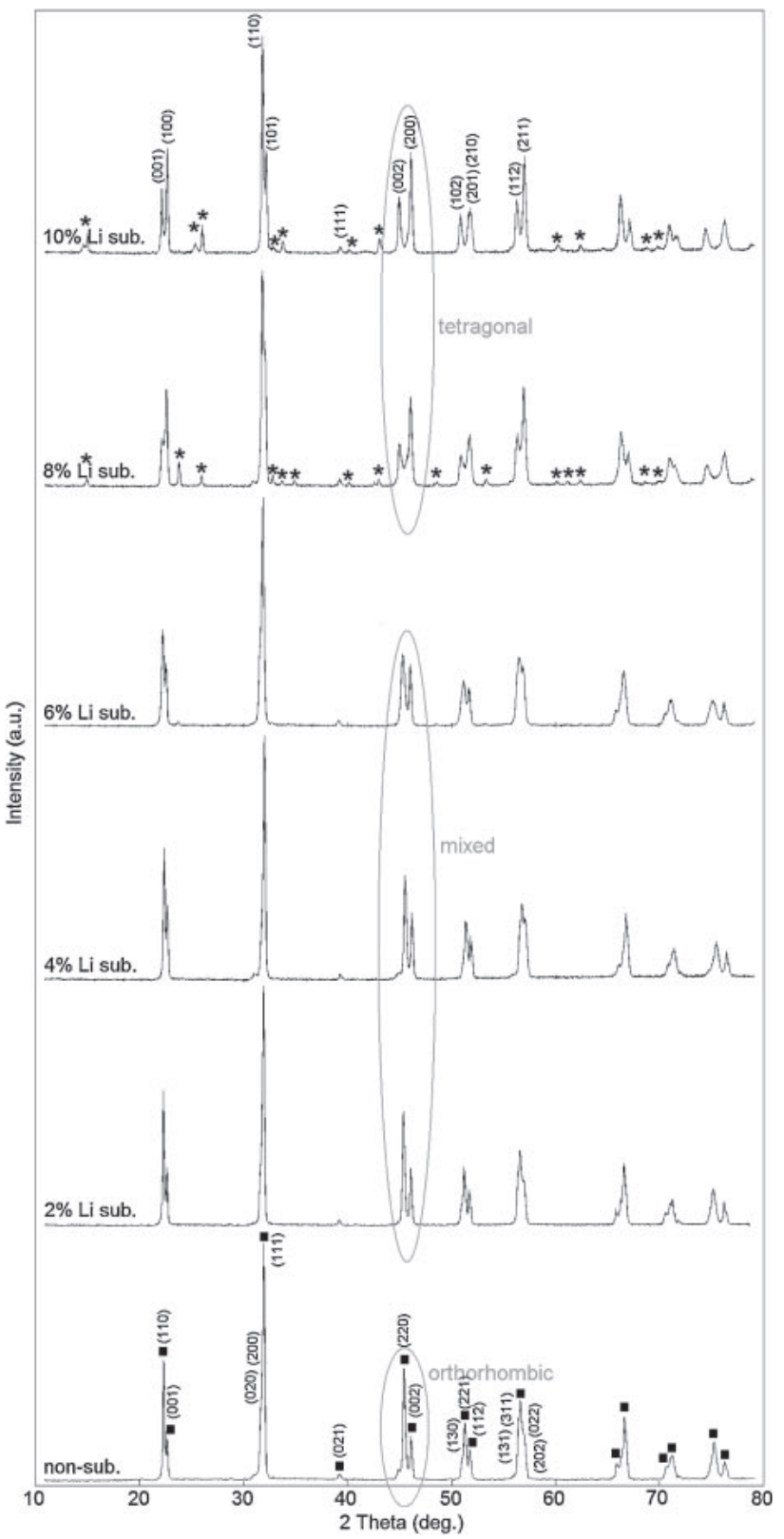

Fig. 1. X-ray diffraction data of KLNN compositions; peaks suited to $\mathrm{KNbO}_{3}(\square)$ and appeared secondary phases $\left(^{*}\right)$ in 8 and $10 \% \mathrm{Li}$ substituted samples were indicated.

diffraction pattern of $8 \% \mathrm{Li}$ substituted sample. Tetragonal KNN phases were identified using tetragonal $\mathrm{KNbO}_{3}$ phase (JCPDS: 71-0945). These circumstances pointed out the crystallographic transition from orthorhombic to tetragonal symmetry, and the tetragonal to orthorhombic phase ratio increased with increasing Li substitution.

$\mathrm{Li}$ atoms replaced the $\mathrm{A}$ sites in $\mathrm{ABO}_{3}$ sub-cell of perovskite structure and this replacement caused a large distortion in the unit cell due to the difference in the atomic radius of $\mathrm{Li}^{10)}$ It was concluded that, a mixture of the orthorhombic and tetragonal phases existed in the samples of 2, 4 and $6 \% \mathrm{Li}$ substituted. The KLNN samples with 8 and $10 \%$ Li were identified as fully tetragonal.

Figure 2 shows the extended $X$-ray diffraction patterns in the $2 \theta$ range of $20-50^{\circ}$ for all compositions. Several secondary crystalline phases were identified for all compositions. For pure 

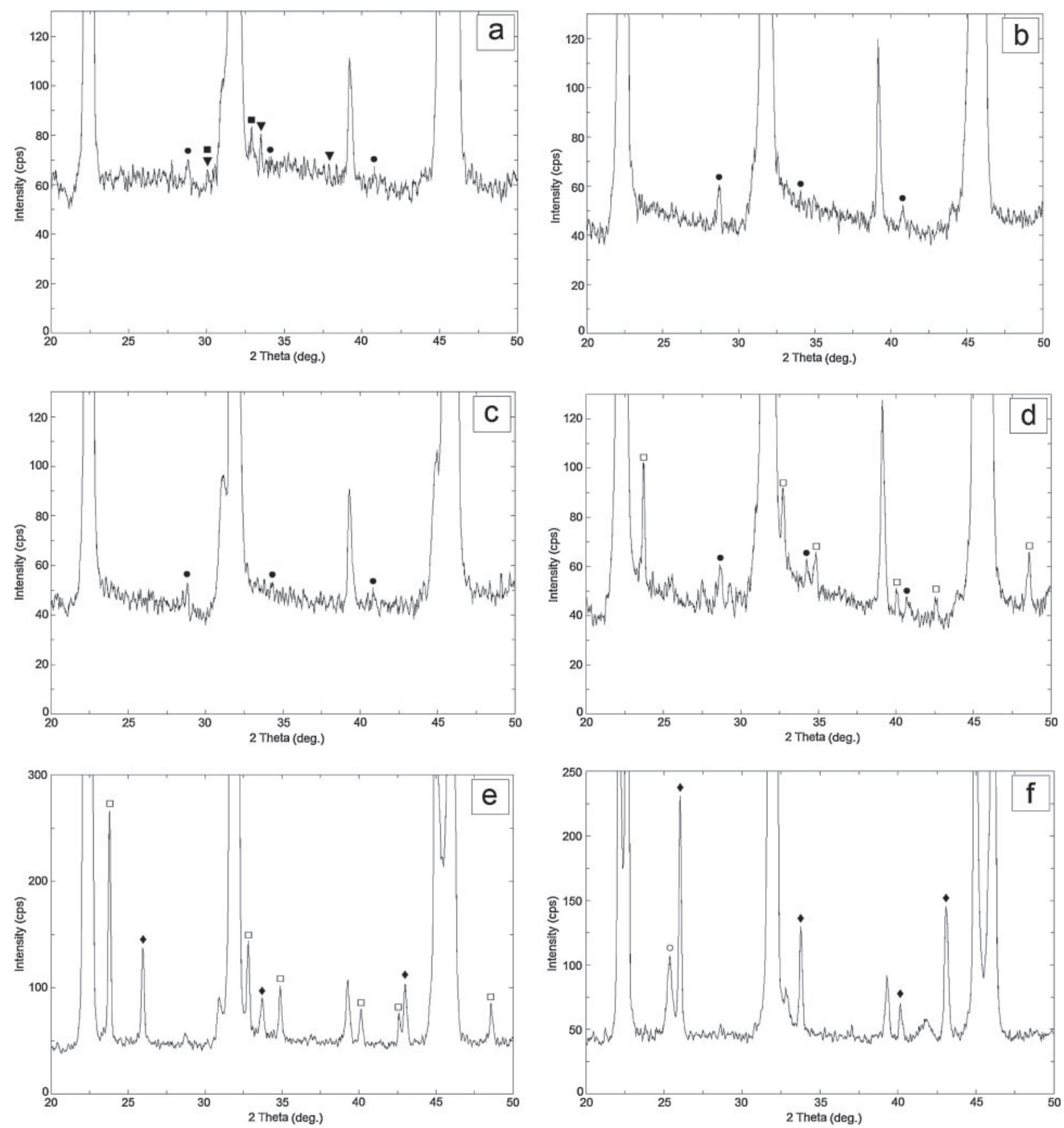

Fig. 2. Extended diffraction patterns show secondary phases of possibly $\mathrm{K}_{3} \mathrm{NbO}_{4}(\boldsymbol{\bullet}), \mathrm{KNbO}_{3}(\boldsymbol{\square}), \mathrm{NaNbO}_{3}(\boldsymbol{\nabla}), \mathrm{LiNbO}_{3}$ $(\square), \mathrm{Li}_{3} \mathrm{NbO}_{4}(\diamond)$ and possibly $\mathrm{K}_{3} \mathrm{Li}_{2} \mathrm{Nb}_{5} \mathrm{O}_{15}(\bigcirc)$, take place in structure of; (a) non-substituted $\mathrm{KNN}$, (b) $2 \%$, (c) $4 \%$, (d) $6 \%$, (e) $8 \%$, (f) $10 \%$, Li substituted KNN ceramics.

$\mathrm{KNN}$, two peaks were appeared at positions between 32.5 and $35^{\circ}$. These peaks were considered as secondary crystalline phases of $\mathrm{NaNbO}_{3}$ (JCPDS: 37-1076) and $\mathrm{KNbO}_{3}$ (JCPDS: 31-1058). Other possible peak-positions belong to these phases were also indicated on diffraction pattern. One more secondary crystalline phase which had a diffraction peak at about $2 \theta=28.5^{\circ}$ was identified and any alkali niobate phase except $\mathrm{K}_{3} \mathrm{NbO}_{4}$ (JCPDS: 52-1895) could not be suited or found close to observed diffraction pattern. A small shift to lower $2 \theta$ values was observed in expected peak position of aforesaid potassium niobate phase and this peak was assumed to belong to $\mathrm{K}_{3} \mathrm{NbO}_{4}$ based structure with a distorted unit cell. The potassium niobate based structure became obvious while two secondary phases of $\mathrm{NaNbO}_{3}$ and $\mathrm{KNbO}_{3}$ disappeared in the diffraction pattern of $4 \% \mathrm{Li}$ substituted samples which were shown in Fig. 2(c). The hexagonal $\mathrm{LiNbO}_{3}$ (JCPDS: 20-0631) crystalline phase was identified in XRD pattern of $6 \% \mathrm{Li}$ substituted in addition to $\mathrm{K}_{3} \mathrm{NbO}_{4}$ based structure [Fig. 2(d)]. This sample was also determined as the mixture of tetragonal and orthorhombic KNN phases. This result revealed that, hexagonal $\mathrm{LiNbO}_{3}$ phase crystallized simultaneously with KNN phase under solubility limit of $\mathrm{Li}$ in $\mathrm{KNN}$. For the sample of $8 \% \mathrm{Li}$ substituted, the 

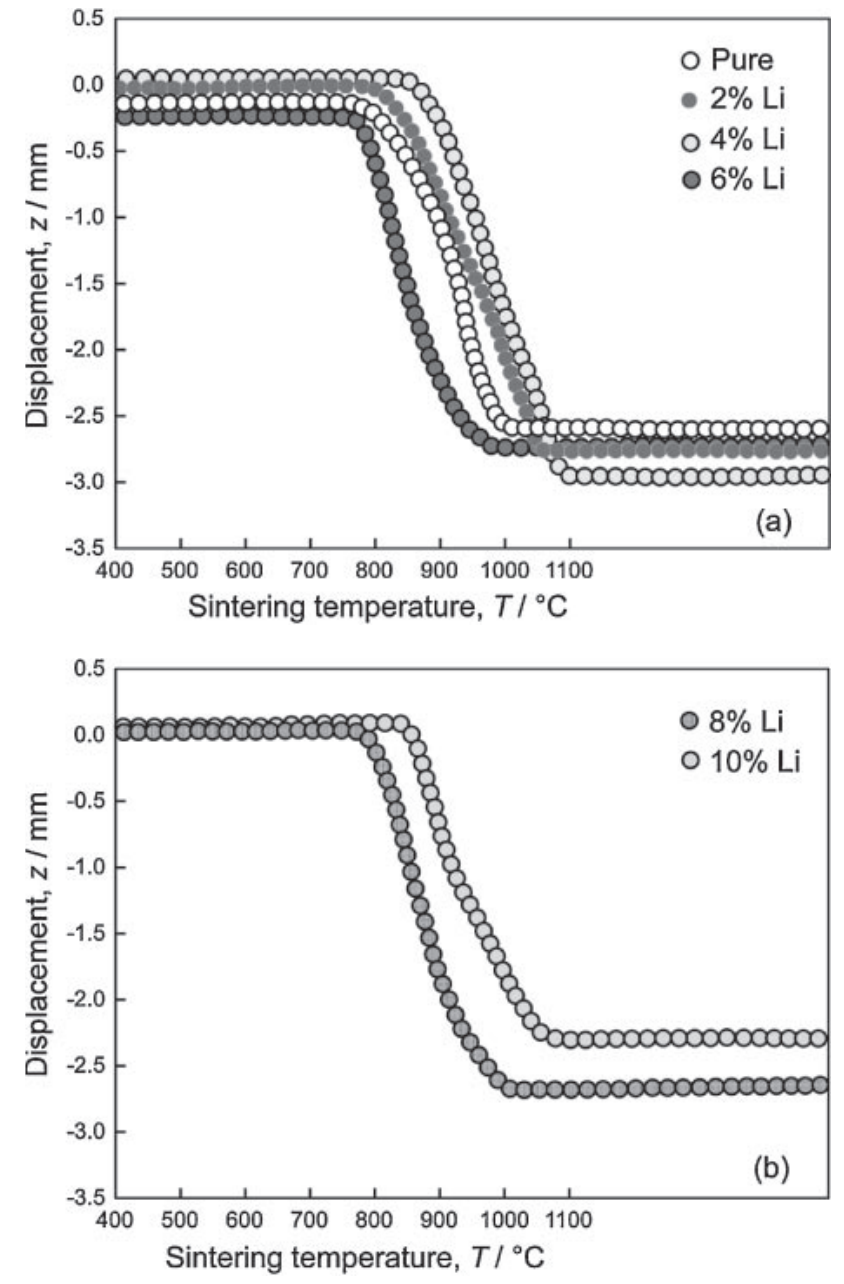

Fig. 3. Sintering behavior of samples as shrinkage curves; (a) nonsubstituted $\mathrm{KNN}, 2,4$, and $6 \%$, (b) 8 and $10 \% \mathrm{Li}$ substituted $\mathrm{KNN}$ ceramics.

relative intensity of $\mathrm{LiNbO}_{3}$ phase increased [Fig. 2(e)] and a new secondary crystalline phase was identified which assumed to belong to a body centered cubic $\mathrm{Li}_{3} \mathrm{NbO}_{4}$ (JCPDS: 16-0459). In the XRD pattern of the sample with $10 \% \mathrm{Li}$ substituted [Fig. 2(f)], $\mathrm{LiNbO}_{3}$ phase disappeared and the relative intensity of $\mathrm{Li}_{3} \mathrm{NbO}_{4}$ phase increased. Furthermore, a diffraction peak appeared at $2 \theta=25.5^{\circ}$ and no alkali niobate phase could be suited except $\mathrm{K}_{3} \mathrm{Li}_{2} \mathrm{Nb}_{5} \mathrm{O}_{15}$ (JCPDS: 52-0157). The most intense peak formation of this phase at $2 \theta=22.4$ could have been caused by overlapping with KLNN phases.

The densification of the specimens during SPS process was evaluated by the displacement of punch rods due to shrinkage of the samples. Figure 3 shows the displacement of KNN and KLNN ceramics and isothermal shrinkage behavior at sintering temperatures for $180 \mathrm{~s}$. Final sintering temperature was determined at the temperature when the shrinkage stopped.

The shrinkage of pure $\mathrm{KNN}$ started at $765^{\circ} \mathrm{C}$ and completed at $1000^{\circ} \mathrm{C}$. The starting temperature of shrinkage increased with increasing $\mathrm{Li}$ content up to $4 \%$. For the specimen with 2 and $4 \%$ $\mathrm{Li}$, starting temperatures of shrinkage were determined as 800 and $850^{\circ} \mathrm{C}$, respectively. The lowest starting temperature of shrinkage $\left(775^{\circ} \mathrm{C}\right)$ was observed with $6 \% \mathrm{Li}$ substituted specimen, and showed similar shrinkage behavior with pure KNN. For the specimens with 8 and $10 \% \mathrm{Li}$, shrinkage started at 800 and
Table 1. Effect of $\mathrm{Li}$ content on relative density, starting and completing temperatures of shrinkage

\begin{tabular}{lccc}
\hline Composition & Relative density $(\%)$ & $T_{\mathrm{s}}\left({ }^{\circ} \mathrm{C}\right)$ & $T_{\mathrm{f}}\left({ }^{\circ} \mathrm{C}\right)$ \\
\hline $\mathrm{K}_{0.5} \mathrm{Na}_{0.5} \mathrm{NbO}_{3}$ & 99.9 & 765 & 1000 \\
$\left(\mathrm{~K}_{0.5} \mathrm{Na}_{0.5}\right)_{0.98} \mathrm{Li}_{0.02} \mathrm{NbO}_{3}$ & 99.7 & 800 & 1050 \\
$\left(\mathrm{~K}_{0,5} \mathrm{Na}_{0,5}\right)_{0,96} \mathrm{Li}_{0,04} \mathrm{NbO}_{3}$ & 99.5 & 850 & 1090 \\
$\left(\mathrm{~K}_{0.5} \mathrm{Na}_{0.5}\right)_{0.94} \mathrm{Li}_{0.06} \mathrm{NbO}_{3}$ & 99.2 & 775 & 975 \\
$\left(\mathrm{~K}_{0.5} \mathrm{Na}_{0.5}\right)_{0.92} \mathrm{Li}_{0.08} \mathrm{NbO}_{3}$ & 99.2 & 800 & 1000 \\
$\left(\mathrm{~K}_{0.5} \mathrm{Na}_{0.5}\right)_{0.90} \mathrm{Li}_{0.10} \mathrm{NbO}_{3}$ & 98.8 & 840 & 1050 \\
\hline
\end{tabular}

$840^{\circ} \mathrm{C}$, respectively. For these samples, shrinkage completed at 1000 and $1050^{\circ} \mathrm{C}$.

Different starting and completion temperatures of shrinkage could be explained by the formation of different secondary phases. Temperatures of shrinkage and relative densities of KNN based ceramics are given in Table 1. For pure KNN, main phases were $\mathrm{NaNbO}_{3}$ and $\mathrm{KNbO}_{3}$ with melting temperatures of 1400 and $1080^{\circ} \mathrm{C}$, respectively. ${ }^{18)}$ The content of these two phases decreased for $2 \%$ Li substituted sample and was not observed for the KLNN sample containing 4\% Li. Disappearance of these two alkali niobate phases was attributed to higher sintering temperatures, 1050 and $1090^{\circ} \mathrm{C}$, which possibly induced reactions between these phases producing KNN. Since the melting temperature of $\mathrm{LiNbO}_{3}, 1257^{\circ} \mathrm{C}$, was lower than that of $\mathrm{NaNbO}_{3}$, for the sample $6 \% \mathrm{Li}$ substituted, the sintering temperature was determined as the lowest, $975^{\circ} \mathrm{C}$, due to the disappearance of this secondary phase. The formation of high melting temperature $\mathrm{Li}_{3} \mathrm{NbO}_{4}, 1408^{\circ} \mathrm{C}$, resulted in both high starting and completion temperatures for 8 and $10 \% \mathrm{Li}$ substituted samples. The relative densities of the samples (Table 1) slightly decreased with increasing $\mathrm{Li}$ content. The relative density of pure $\mathrm{KNN}$ was about $99.9 \%$, while that of specimen with $10 \% \mathrm{Li}$ reached 98.8\%. These results are compatible with hot pressed ceramics given in literature. It was considered that, followed sintering method, i.e. controlling the shrinkage behavior continuously, was favorable to achieve high density KLNN ceramics, when these results were compared with the similar reported studies in which a constant sintering temperature was applied for all compositions. ${ }^{15)}$

\subsection{Microstructure}

Microstructures of fracture surfaces of the samples with compositions of $\left(\mathrm{K}_{0.5} \mathrm{Na}_{0.5}\right)_{1-x} \mathrm{Li}_{x} \mathrm{NbO}_{3}(x=0-10)$ are shown in Fig. 4. The microstructure of the pure $\mathrm{KNN}$ consisted of rectangular shaped grains $1-5 \mu \mathrm{m}$ in size [Fig. 4(a)]. The fracture mechanism was mainly intergranular. Figure 4(b) shows the microstructure of the sample with $2 \% \mathrm{Li}$. Grain size was determined about $2 \mu \mathrm{m}$ and fracture took place in the grains. For $4 \% \mathrm{Li}$ substituted $\mathrm{KNN}$ sample grain size was determined about $5 \mu \mathrm{m}$ [Fig. 4(c)]. For the samples containing 6,8 and $10 \% \mathrm{Li}$, grains were in perfect rectangular shapes. The grain size exceeded $15 \mu \mathrm{m}$ for the sample containing 10\%. Although SPS method enables to control the grain growth mechanism, a significant enlargement in grain size was observed. This result pointed out the grain growth of this sample could be due to high lithium substitution. Probably lithium niobate with high melting point or potassium lithium niobate secondary phases show seeding effect.

A remarkable cleavage behavior was observed for $8 \% \mathrm{Li}$ substituted sample. The magnified view of fracture surface of this sample is shown in Fig. 5. The periodic bright and darker fields in a shape of narrow strips appeared on fracture surface of a 

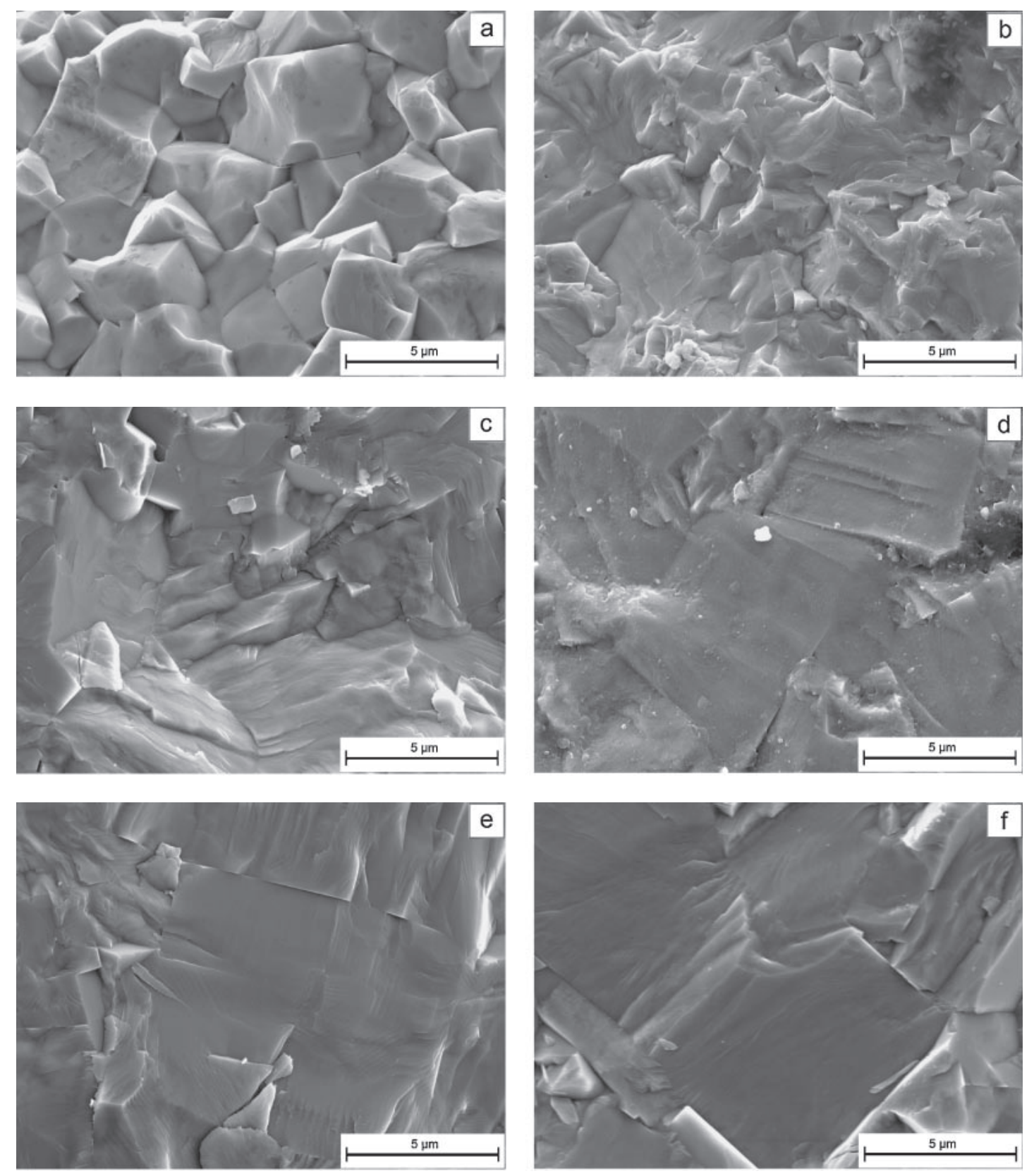

Fig. 4. Micrographs of (a) non-substituted KNN, (b) 2\%, (c) 4\%, (d) 6\%, (e) 8\%, (f) 10\%, Li substituted KNN ceramics.

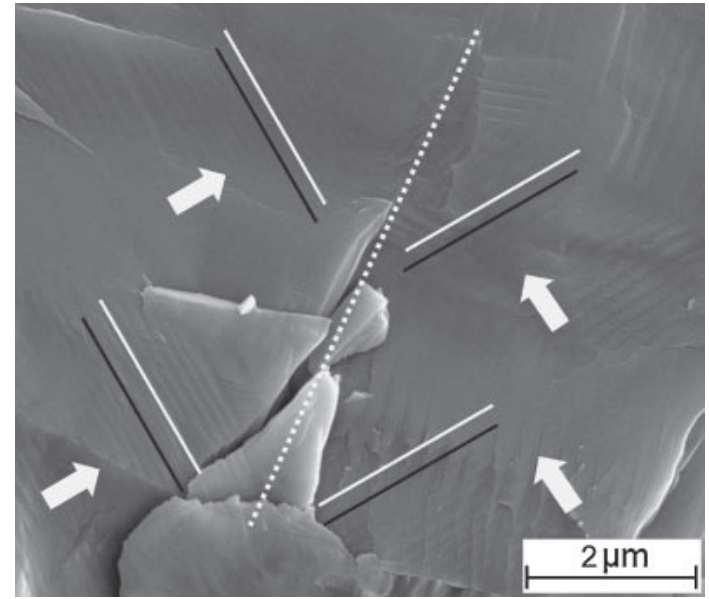

Fig. 5. Ferroelectric domain orientations in $8 \% \mathrm{Li}$ substituted $\mathrm{KNN}$ sample. grain. These oriented fields were assumed to be ferroelectric domains in opposite orientations, which showed different fracture behavior like polished and etched KNN surfaces. It was reported that in the literature, ferroelectric domains of a KNN single crystal was clearly observed by using SEM method from polished sample. ${ }^{19)}$ It is clear in Fig. 5, two different orientation directions (normal to the strips) existed and these directions were indicated with white arrows. Some of the brighter (white lines) and darker fields (black lines) in different orientation directions were indicated. The angle between red lines in different directions was determined as $90^{\circ}$. It was considered that, $90^{\circ}$ domain boundary took place between these strips which were in different orientation direction and white dotted line signed on the micrograph indicated that the location of possible $90^{\circ}$ domain boundary. Also $180^{\circ}$ domain boundaries were evaluated taking placed between brighter and darker fields, but it is impossible to show polarization directions without taking 

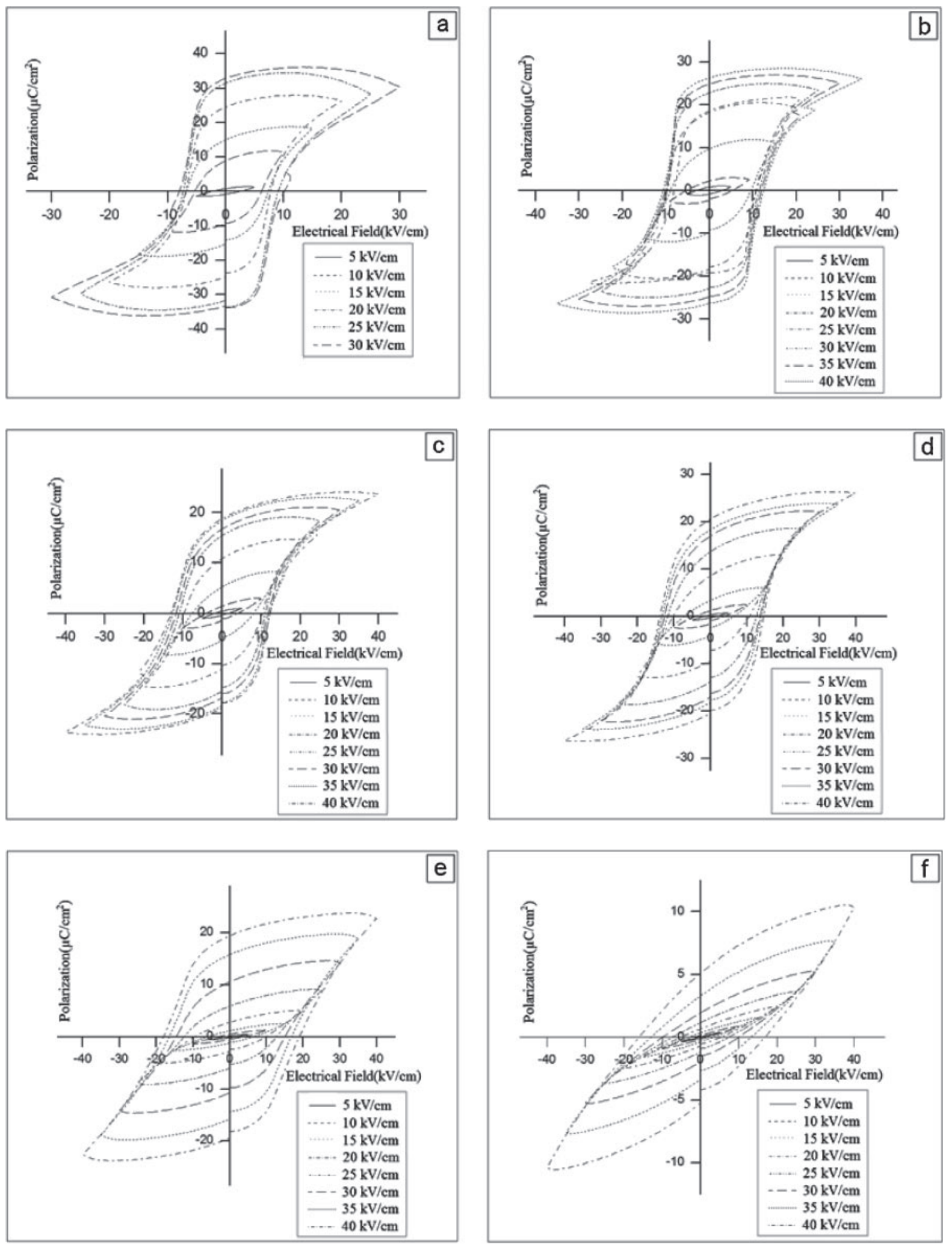

Fig. 6. Hysteresis loops of (a) non-substituted KNN, (b) $2 \%$, (c) 4\%, (d) 6\%, (e) $8 \%$, (f) $10 \%$, Li substituted KNN ceramics.

diffraction pattern from these domains using high resolution transmission electron microscopy (HRTEM) method. These two type domain boundaries were evaluated as common for whole grain and any other orientation was not observed. These assumptions were also in agreement with the results of crystallo- graphic investigation for $8 \% \mathrm{Li}$ substituted composition which was fully tetragonal. It was referred in literature, only 90 and $180^{\circ}$ domain boundaries exist for tetragonal perovskite structures. For orthorhombic perovskites, 60 and $120^{\circ}$ domain boundaries can be constituted in addition to 90 and $180^{\circ}$ domain 
boundaries. ${ }^{20)-22)}$ Although these oriented fields observed in fracture cross section images of 2, 4 and $6 \% \mathrm{Li}$ substituted samples, strips are very narrow and domain boundaries are not seen clearly. It is an ongoing study of investigation on ferroelectric domains and domain boundaries of all orthorhombic, mixed and tetragonal KLNN structures and results will be reported in another paper.

\subsection{Ferroelectric properties}

The polarization behavior of $\left(\mathrm{K}_{0.5} \mathrm{Na}_{0.5}\right)_{1-x} \mathrm{Li}_{x} \mathrm{NbO}_{3}(x=0-10)$ was observed under various electric field intensity and cycle periods. For pure KNN, polarization curves were obtained at the electric field of $30 \mathrm{kV} / \mathrm{cm}$. Dielectric break-down was occurred when this electric field intensity value was exceeded for this sample. Other samples polarized at the electric field of $40 \mathrm{kV} / \mathrm{cm}$ and hysteresis curves were sketched. This electric field intensity value was determined as saturation point for maximum polarization. Hysteresis curves of the samples are shown in Fig. 6. Maximum and remnant polarization were determined as 27 and $20 \mu \mathrm{C} / \mathrm{cm}^{2}$, respectively for pure $\mathrm{KNN}$ sample at the electric field of $20 \mathrm{kV} / \mathrm{cm}$. For larger electric field intensities, remnant polarization was determined to be larger than that of maximum polarization for not substituted KNN sample. This result was attributed to leakage contribution. Existence of anti-ferroelectric sodium niobate phase may have some contribution on rounded hysteresis loops. Total spontaneous polarization of this antiferroelectric phase under applied electric field was zero and any extra effect originating from this phase did not contribute to the maximum polarization value. The dipoles of this phase aligned parallel to dipoles of $\mathrm{KNN}$ and originated the enlargement of polarization while quenching the electric field. This effect was reported before in literature. ${ }^{23)}$ The polarization behavior of the 4 and 6\% Li substituted samples are shown in Figs. 6(c) and 6(d), respectively. Maximum polarization values of these samples were measured at the electric field of $40 \mathrm{kV} / \mathrm{cm}$ for $300 \mathrm{~ms}$ cycle period. Maximum polarization values were obtained as 24 and $26 \mu \mathrm{C} / \mathrm{cm}^{2}$ respectively for the 4 and $6 \% \mathrm{Li}$ substituted samples. It was observed that, remnant polarization values reduced with increasing Li content. Small nails appeared on hysteresis curves of 2 and $4 \%$ substituted samples [Figs. 6(b) and 6(c)]. This behavior pointed out that, $300 \mathrm{~ms}$ was insufficient as a cycle period. The composition of $\left(\mathrm{K}_{0.5} \mathrm{Na}_{0.5}\right)_{0.94} \mathrm{Li}_{0.06} \mathrm{NbO}_{3}$ represented an optimal ferroelectric behavior [Fig. 6(d)]. Furthermore, a degradation hysteretic behavior was pointed out electrical conductivity for the samples containing 8 and 10\% Li [Figs. 6(e) and 6(f)]. Degradation in hysteresis loop could be originating from the existence of cubic $\mathrm{Li}_{3} \mathrm{NbO}_{4}$ secondary phase more than tetragonal $\mathrm{LiNbO}_{3}$ for the samples containing 8 and $10 \% \mathrm{Li}$. $\mathrm{LiNbO}_{3}$ is a well known ferroelectric crystal and existence of this secondary phase in $6 \% \mathrm{Li}$ substituted $\mathrm{KNN}$ shows no degradation in hysteresis loops. Ferroelectric $\mathrm{LiNbO}_{3}$ phase may have extra dipole contribution to polarization.

\section{Conclusions}

$\mathrm{Li}$ modified KNN lead-free piezoelectric ceramics were prepared by spark plasma sintering. Using current controlled sintering method made it possible to reach high relative densities up to $99.9 \%$. Secondary phases revealed in KNN ceramics which has a significant contribution to ferroelectric properties besides of orthorhombic to tetragonal phase transition. Lithium niobate phase in cubic crystal structure $\left(\mathrm{Li}_{3} \mathrm{NbO}_{4}\right)$ degrades hysteretic behavior.

Acknowledgement Authors would like to thank to Dr. S. Alkoy and Dr. H. Yilmaz from Gebze Institute of Technology for the measurement of ferroelectric properties.

\section{References}

1) Y. Saito, H. Takao, T. Tani, T. Nonoyama, T. K. Takatori, T. Homma, T. Nagaya and M. Nakamura, Nature, 432, 84-87 (2004).

2) L. Egerton and D. M. Dillon, J. Am. Ceram. Soc., 42, 438-442 (1959).

3) R. E. Jaeger and L. Egerton, J. Am. Ceram. Soc., 45, 209-213 (1962).

4) L. Egerton and C. A. Bieling, Am. Ceram. Soc. Bull., 47, 1151-1156 (1968).

5) R. Wang, R. Xie, T. Sekiya and Y. Shimojo, Mater. Res. Bull., 39, 1709-1715 (2004).

6) J. F. Li, K. Wang, B. P. Zhang and L. M. Ming, J. Am. Ceram. Soc., 89, 706-709 (2006).

7) B. P. Zhang, J. F. Li, K. Wang and H. Zhang, J. Am. Ceram. Soc., 89, 1605-1609 (2006).

8) J. Kroupa, J. Petzelt, B. Malic and M. Kosec, J. Phys. D: Appl. Phys., 38, 679-681 (2005).

9) Y. Guo, K. Kakimoto and H. Ohsato, Mater. Lett., 59, 241-244 (2005).

10) Y. Guo, K. Kakimoto and H. Ohsato, Appl. Phys. Lett., 85, 4121-4123 (2004).

11) G. Z. Zang, J. F. Wang, H. C. Chen, W. B. Su, C. M. Wang, P. Qi, B. Q. Ming and T. R. Shrout, Appl. Phys. Lett., 88, 212908 (2006).

12) K. Wang and J. F. Li, Appl. Phys. Lett., 91, 262902 (2007).

13) J. Tellier, B. Malic Dkhil, D. Jenko, J. Cilensek and M. Kosec, Solid State Sci., 11, 320-324 (2009).

14) G. Shirane, R. Newnham and R. Pepinsky, Phys. Rev., 96, 581588 (1954).

15) P. Zhao, B. Zhang, K. Wang, L. Zhang and H. Zhang, J. Univ. Sci. Technol. Beijing, 15, 314-319 (2008).

16) X. K. Niu, J. L. Zhang, L. Wu, P. Zheng, M. L. Zhao and C. L. Wang, Solid State Commun., 146, 395-398 (2008).

17) P. Bomlai, P. Wichianrat, S. Muensit and S. J. Milne, J. Am. Ceram. Soc., 90, 1650-1655 (2007)

18) A. P. Pivovarova, V. I. Strakhov and V. P. Popov, Refract. Ind. Ceram., 42, 285-287 (2001).

19) A. Bencan, E. Tchernychova, M. Godec, J. Fisher and M. Kosec, Microsc. Microanal., 15, 435-440 (2009).

20) J. Hirohashi, K. Yamada, H. Kamio, M. Uchida and S. Shichijyo, J. Appl. Phys., 98, 034107 (2005).

21) D. Damjanovic, Rep. Prog. Phys., 61, 1267-1324 (1998).

22) R. Herber, G. A. Schneider, S. Wagner and M. J. Hoffman, Appl. Phys. Lett., 90, 905-908 (2007).

23) A. J. Paula, R. Parra, M. A. Zaghete and J. A. Varela, Solid State Commun., 149, 1587-1590 (2009). 